\title{
PENGARUH SENAM YOGA TERHADAP PENURUNAN TEKANAN DARAH PADA LANSIA YANG MENGALAMI HIPERTENSI (Studi di Desa Plandi Kecamatan Jombang Kabupaten Jombang)
}

\author{
Rofbig Adi Sena ${ }^{1}$ Hindyah Ike $S^{2}$ Sumatri Endah Purnamaningsih ${ }^{3}$ \\ STIKes Borneo Cendekia Medika Pangkalan Bun \\ ${ }^{1}$ email : rofbigadisena@gmail.com, ${ }^{2}$ email : .hindyahike@yahoo.com, ${ }^{3}$ email : \\ sumatriendah@gmail.com
}

\begin{abstract}
ABSTRAK
Masalah hipertensi pada lansia dikarenakan adanya riwayat hipertensi dalam keluarga, kelebihan berat badan yang diikuti dengan kurangnya kepatuhan dalam diet, dikarenakan perubahan secara global dengan mudahnya mendapatkan makanan siap saji membuat konsumsi sayuran segar dan serat berkurang, kemudian konsumsi garam, lemak, gula dan kalori yang terus menerus meningkat. Tujuan penelitian ini adalah Menganalisa Pengaruh senam Yoga terhadap penurunan tekanan darah pada lansia yang mengalami hipertensi. Desain penelitian ini adalah pra eksperimen one group pre test post test desaign. Populasinya semua lansia hipertensi di Desa Plandi Kecamatan Jombang Kabupaten Jombang yang berjumlah 68 orang. Tehnik sampling menggunakan simple random samplingdengan sampelnya sejumlah 20 orang. Instrumen penelitian menggunakan lembar observasidengan pengolahan data editing, coding, scoring, tabulating dan uji statistik menggunakan Wilcoxon $\alpha=0,05$. Hasil penelitian tekanan darah pada lansia yang mengalami hipertensi sebelum senam yogaadalah termasuk dalam kategori sedang sejumlah 14 responden (70\%). Tekanan darah pada lansia yang mengalami hipertensi sesudah senam yoga adalah termasuk dalam kategori normal tinggi sejumlah 11 responden (55\%). Uji Wilcoxon menunjukkan bahwa nilai signifikansi $\mathrm{p}=0,00<\alpha(0,05)$, sehingga $\mathrm{H}_{0}$ ditolak dan $\mathrm{H}_{1}$ diterima. Penelitian ini dapat disimpulkan bahwa ada Pengaruh senam Yoga terhadap penurunan tekanan darah pada lansia yang mengalami hipertensi.
\end{abstract}

Kata Kunci : Hipertensi, lansia, tekanan darah, yoga.

\section{INFLUENCE OF YOGA EXERCISE ON BLOOD PRESSURE DECREASE IN ELDERLY PATIENT WHO HAVE HYPERTENSION (Study in Plandi Village Jombang District Jombang Regency)}

\begin{abstract}
The problem of hypertension in the elderly is due to family history of hypertension, overweight followed by lack of adherence in the diet, due to global changes with the ease of getting fast food makes the consumption of fresh vegetables and fiber is reduced, then consumption of salt, fat, sugar and calories Continues to increase. The purpose of this
\end{abstract}


study is to Analyze the Effect of Yoga exercises on the decrease of blood pressure in elderly who have hypertension.The design of this study was pre experimental one group pre test post test desaign. Population of all elderly hypertension in Plandi Village Jombang District Jombang Regency, amounting to 68 people. The sampling technique uses simple random sampling with a sample of 20 people. The research instrument used observation sheet with data processing editing, coding, scoring, tabulating and statistical test using wilcoxon $\alpha=$ 0,05.The result of blood pressure research in elderly who have hypertension before yoga gymnastic is included in the category of moderate is 14 respondent (70\%). Blood pressure in elderly who have hypertension after yoga gymnastics is included in the category of normal high number of 11 respondents (55\%). The wilcoxon test shows that the significance value $p=0,00<\alpha(0,05)$, so $H_{0}$ is rejected and $H_{1}$ is accepted.This research can be concluded that there is influence yoga excercise to decrease blood pressure in elderly who have hypertension.

Keywords: hypertension, elderly, blood pressure, yoga.

\section{PENDAHULUAN}

Lanjut usia merupakan usia yang beresiko tinggi terhadap penyakit-penyakit degeneratif seperti Penyakit Jantung Koroner (PJK), hipertensi, diabetes mellitus, rematik, dan kanker. Hipertensi merupakan penyakit yang sering dialami oleh lanjut usia. Hipertensi sering disebut sebagai pembunuh terselubung. Hipertensi tidak memberikan gejala kepada penderita. Namun bukan berarti hal ini tidak berbahaya. Pada umumnya semua gangguan medis yang timbul biasanya diikuti dengan tanda dan gejalanya. Namun hal ini tidak berlaku pada hipertensi. Hipertensi cenderung meningkat dengan bertambahnya usia. Fenomena yang ada menunjukkan hipertensi lebih banyak menyerang pada lansia. Perbandingan hipertensi lebih banyak menyerang laki-laki dari pada perempuan (Santoso, 2010, 56).

Berdasarkan data dari Badan Pusat Statistik (BPS) tahun 2015 jumlah pra lansia di Jawa Timur mencapai 4.209.817 jiwa atau $(11,14 \%)$ dari jumlah penduduk Jawa Timur yang tercatat 37.794.003 jiwa (Dinas Komunikasi dan Informatika Prov.Jatim, 2015, 6).Hasil survei kesehatan rumah tangga menunjukkan bahwa pada tahun 2015 sekitar 15-20\%

masyarakat Indonesia menderita hipertensi dan prevalensinya semakin meningkat. Prevalensi di tahun 2016 terlihat meningkat, yaitu dari $1,7 \%(6,098)$, menjadi 2,6\% (7,244) (Depkes RI, 2016, 3). Berdasarkan data Dari Dinas Kesehatan Propinsi Jawa Timur pada tahun 2015 prevelensi hipertensi sejumlah 2,6\% (Profil Kesehatan Jawa Timur, 2015, 25). Hasil dari pemeriksaan ini ditemukan penderita hipertensi sebesar 37.604 $(16,11 \%)$ (Profil Kesehatan Jombang, 2015, 30).

Salah satu penyebab kejadian hipertensi adalah gaya hidup yang kurang sehat. Gaya hidup dapat diklasifikasikan menjadi beberapa komponen yang berkaitan 
dengan kejadian hipertensi yaitu terdiri dari minum kopi, merokok, merawat berat badan tetap ideal, aktif beraktivitas dan minum alkohol. Hal-hal tersebut dapat menyebabkan terjadinya hipertensi dimana merokok dapat merusak jantung dan sirkulasi darah dan meningkatkan resiko penyakit jantung dan stroke, merawat badan tetap ideal yaitu aktif beraktivitas dapat melindungi dari penyakit hipertensi. Selain itu, mengkonsumsi alkohol berlebih dapat menyebabkan resistensi pada terapi anti hipertensi dan berisiko terjadinya beberapa penyakit lain seperti stroke dan jantung (Yusuf, 2011, 3).

Penanganan hipertensi pada lansia dapat di lakukan dengan cara farmakologi dan non farmakologi. Penanganan secara farmakologi dapat dilakukan dengan menggunakan obat-obatan kimiawi, sedangkan penanganan pada non farmakologi untuk mengatasi hipertensi pada lansia yaitu dengan melakukan senam yoga. Senam yoga dapat dilakukan selama tiga kali dalam seminggu selama 15 menit. Latihan yoga dapat menstimulasi hormon endorphin yang ada didalam tubuh. Endorphin merupakan neuropeptide yang diproduksi pada saat relaks/tenang. Endorphin merupakan hormon yang diproduksi oleh susunan syaraf pusat. Endorphin berguna dalam membuat perasaan nyaman dan menurunkan tekanan darah tinggi karena sifatnya sebagai penenang alami (Sindhu, 2011, 3).

\section{METODE PENELITIAN}

Jenis penelitian ini adalah pre eksperimen dengan menggunakan one group pre test post test design. Populasi dalam penelitian ini adalah semua lansia hipertensi berjumlah 68 orang. Dengan menggunakan penentuan sampel yang dikembangkan oleh Roscoe dalam Sugiyono (2010, 48), untuk penelitian eksperimen sederhana yang menggunakan kelompok eksperimen dan kelompok kontrol, maka jumlah anggota sampel masing-masing antara 10 sampai dengan 20. Teknik sampling yang digunakan dalam penelitian ini adalah probability sampling dengan metode simple random sampling sehingga didapatkan sample sebanyak 20 responden. Alat pengumpulan data berupa lembar observasi dan pengukur tekanan darah yaitu sphygmomanometer.

\section{HASIL DAN PEMBAHASAN}

Tabel 1 Distribusi Frekuensi Responden Berdasarkan umur di Desa Plandi Kecamatan Jombang Kabupaten Jombang 2017

\begin{tabular}{cccc}
\hline No & Umur & Frekuensi & Persentase (\%) \\
\hline 1 & $\begin{array}{l}60-65 \\
\text { tahun }\end{array}$ & 14 & 70.0 \\
2 & $\begin{array}{l}66-74 \\
\text { tahun }\end{array}$ & 6 & 30.0 \\
\hline & Total & 20 & 100.0 \\
\hline
\end{tabular}

Sumber : Data primer 2017

Tabel 1 menunjukkan bahwa dari 68 responden sebagian besar berumur 60-65 tahun yaitu sejumlah 14 responden $(70 \%)$.

Tabel 2 Distribusi Frekuensi Responden Berdasarkan tingkat pendidikan di Desa Plandi Kecamatan Jombang Kabupaten Jombang 2017 


\begin{tabular}{cccc}
\hline No & Pendidikan & Frekuensi & $\begin{array}{c}\text { Persentase } \\
(\boldsymbol{\%})\end{array}$ \\
\hline 1 & SD & 16 & 80.0 \\
2 & SMP & 4 & 20.0 \\
\hline & Total & 20 & 100.0 \\
\hline
\end{tabular}

Sumber : Data primer 2017

Tabel 2 menunjukkan bahwa dari 20 responden hampir seluruhnya berpendidikan SD sejumlah 16 responden (80\%).

Tabel 3 Distribusi Frekuensi Responden Berdasarkan pekerjaan di Desa Plandi Kecamatan Jombang Kabupaten Jombang 2017.

\begin{tabular}{cccc}
\hline No & Pekerjaan & Frekuensi & $\begin{array}{c}\text { Persentase } \\
(\boldsymbol{\%})\end{array}$ \\
\hline 1 & Bekerja & 4 & 20.0 \\
2 & $\begin{array}{c}\text { Tidak } \\
\text { bekerja }\end{array}$ & 16 & 80.0 \\
\hline & Total & 20 & 100.0 \\
\hline
\end{tabular}

Sumber : Data primer 2017

Tabel 3 menunjukkan bahwa dari 20 responden hampir seluruhnya tidak bekerja sejumlah 16 responden $(80 \%)$.

Tabel 4 Distribusi Frekuensi Responden Berdasarkan pernah mendapatkan informasi di Desa Plandi Kecamatan Jombang Kabupaten Jombang 2017

\begin{tabular}{cccc}
\hline No & Informasi & Frekuensi & $\begin{array}{c}\text { Persentase } \\
(\mathbf{\%})\end{array}$ \\
\hline 1 & Pernah & 18 & 90.0 \\
2 & $\begin{array}{c}\text { Tidak } \\
\text { pernah }\end{array}$ & 2 & 10.0 \\
\hline & Total & 20 & 100.0
\end{tabular}

Sumber : Data primer 2017

Tabel 4 menunjukkan bahwa dari 20 responden hampir seluruhnya tidak pernah mendapatkan informasi sejumlah 18 responden $(90 \%)$.
Tabel 5 Distribusi frekuensi Responden Berdasarkan sumber informasi di Desa Plandi Kecamatan Jombang Kabupaten Jombang 2017

\begin{tabular}{|c|c|c|c|}
\hline No & $\begin{array}{c}\text { Sumber } \\
\text { informasi }\end{array}$ & Frekuensi & $\begin{array}{c}\text { Persentase } \\
(\%)\end{array}$ \\
\hline 1 & $\begin{array}{c}\text { Petugas } \\
\text { kesehatan }\end{array}$ & 18 & 100 \\
\hline 2 & Majalah & 0 & 0 \\
\hline 3 & Radio/TV & 0 & 0 \\
\hline \multirow[t]{2}{*}{4} & Internet & 0 & 0 \\
\hline & Total & 18 & 100.0 \\
\hline
\end{tabular}

Sumber : Data primer 2017

Tabel 5 menunjukkan bahwa dari 20 responden seluruhnya mendapatkan sumber informasi dari petugas kesehatan sejumlah 18 responden (100\%).

Tabel 6 Distribusi Frekuensi Responden Berdasarkan tekanan darah pada lansia yang mengalami hipertensi sebelum senam yoga di Desa Plandi Kecamatan Jombang Kabupaten Jombang 2017

\begin{tabular}{cccc}
\hline No & Kategori & Frekuensi & $\begin{array}{c}\text { Persentase } \\
(\mathbf{\%})\end{array}$ \\
\hline 1 & $\begin{array}{c}\text { Stadium 2 } \\
\text { (Sedang) }\end{array}$ & 14 & 70.0 \\
2 & $\begin{array}{c}\text { Stadium 1 } \\
\text { (Ringan) }\end{array}$ & 6 & 30.0 \\
\hline & Total & 20 & 100.0 \\
\hline
\end{tabular}

Sumber : Data primer 2017

Tabel 6 menunjukkan bahwa dari 20 responden sebagian besar tekanan darah pada lansia yang mengalami hipertensi sebelum senam yogaadalah sedang sejumlah 14 responden (70\%).

Tabel 7Distribusi Frekuensi Responden Berdasarkan tekanan darah pada lansia yang mengalami hipertensi sesudah senam 
yoga di Desa Plandi Kecamatan Jombang Kabupaten Jombang 2017

\begin{tabular}{cccc}
\hline No & Kategori & Frekuensi & $\begin{array}{c}\text { Persentase } \\
(\%)\end{array}$ \\
\hline 1 & $\begin{array}{c}\text { Stadium 1 } \\
\text { (Ringan) }\end{array}$ & 8 & 40.0 \\
2 & $\begin{array}{c}\text { Normal } \\
\text { tinggi }\end{array}$ & 11 & 55.0 \\
3 & Normal & 1 & 5.0 \\
\hline & Total & 20 & 100.0 \\
\hline
\end{tabular}

Sumber : Data primer 2017

Tabel 7 menunjukkan bahwa dari 20 responden sebagian besar tekanan darah pada lansia yang mengalami hipertensi sesudah senam yoga adalah normal tinggi sejumlah 11 responden $(55 \%)$.

Tabel 8 Tabulasi silang pengaruh senam yoga terhadap penurunan tekanan darah pada lansia yang mengalami hipertensi di Desa Plandi Kecamatan Jombang Kabupaten Jombang 2017.

\begin{tabular}{cccccccccc}
\hline & \multicolumn{3}{c}{ Post test } & & \multicolumn{3}{c}{ Total } \\
\cline { 2 - 8 } Pre test & $\begin{array}{c}\text { Stadium } \\
\text { (Ringan) }\end{array}$ & $\begin{array}{c}\text { Normal } \\
\text { tinggi }\end{array}$ & Normal & \\
\cline { 2 - 9 } & $\sum$ & $\%$ & $\sum$ & $\%$ & $\sum$ & $\%$ & $\sum$ & $\%$ \\
\hline $\begin{array}{c}\text { Stadium 2 } \\
\text { (Sedang) }\end{array}$ & 8 & 40 & 6 & 30 & 0 & 0 & 14 & 70 \\
& & & & & & & & \\
$\begin{array}{c}\text { Stadium 1 } \\
\text { (Ringan) }\end{array}$ & 0 & 0 & 5 & 25 & 1 & 5 & 6 & 30 \\
\hline Total & 8 & 40 & 11 & 55 & 1 & 5 & 20 & 100 \\
\hline Uji Wilcoxon $=0,000$ & $\alpha$ & $=0,05$ & \\
\hline Sumber : Data primer 2017
\end{tabular}

Tabel 8 menunjukkan bahwa dari 20 responden tekanan darah pada lansia yang mengalami hipertensi sebelum senam yogaadalah dalam kategori sedang akan meningkatkan penurunan tekanan darah pada lansia yang mengalami hipertensi sesudah senam yoga adalah dalam kategori ringan sejumlah 8 responden (40\%). Dari Hasil uji statistik wilcoxon diperoleh angka signifikan atau nilai probabilitas $(0,000)$ jauh lebih rendah standart signifikan 0,05 atau $(\mathrm{p}<\alpha)$, dikarenakan nilai $\mathrm{p}<\alpha$, yang berarti ada pengaruh senam yoga terhadap penurunan tekanan darah pada lansia yang mengalami hipertensi di Desa Plandi Kecamatan Jombang Kabupaten Jombang.

\section{PEMBAHASAN}

Tekanan darah pada lansia yang mengalami hipertensi sebelum senam yoga

Tabel 5.6 menunjukkan bahwa dari 20 responden sebagian besar tekanan darah pada lansia yang mengalami hipertensi sebelum senam yoga adalah temasuk dalam kategori sedang yaitu sejumlah 14 responden (70\%). Faktor yang mempengaruhi kejadian hipertensi pada lansia adalah faktor usia dan pekerjaan. Tabel 5.1 menunjukkan bahwa dari 68 responden sebagian besar berumur 60-65 tahun yaitu sejumlah 14 responden $(70 \%)$. Tabel 5.3 menunjukkan bahwa dari 20 responden hampir seluruhnya tidak bekerja sejumlah 16 responden $(80 \%)$.

Menurut peneliti responden yang mengalami kejadian hipertensi ringan dikarenakan responden sudah memasuki masa lansia, yang mengalami penurunan saraf fisik dan pada lansia adanya riwayat hipertensi dalam keluarga, kelebihan berat badan yang diikuti dengan kurangnya kepatuhan dalam diet, dikarenakan perubahan secara global dengan mudahnya 
mendapatkan makanan siap saji membuat konsumsi sayuran segar dan serat berkurang, kemudian konsumsi garam, lemak, gula dan kalori yang terus menerus meningkat. Lansia yang tidak bekerja akan berkurang aktifitas fisiknya dalam menjalankan kehidupan sehari-hari sehingga menyebabkan tekanan darah dalam tubuh menjadi meningkat. Mekanisme meningkatnya tekanan darah pada lansia disebabkan karena seiring bertambahnya umur pada lansia akan menyebabkan terganggunya mekanisme perbaikan sel, selain itu juga diakibatkan oleh kaku dan menebalnya dinding arteri karena telah terjadi arteriosklerosis.

Menurut teori, lansia yang tidak bekerja juga mengurangi aktivitas dalam kehidupan sehari-hari, hal ini sesuai dengan teori yang juga menyatakan bahwa kurang olah raga dan bergerak bisa menyebabkan tekanan darah dalam tubuh meningkat. Aktifitas fisik sangat penting untuk mengendalikan tekanan darah (Sheps, 2009, 15). Aktifitas fisik dapat membuat jantung lebih kuat. Jantung mampu memompa lebih banyak darah dengan hanya sedikit usaha (Sheps, 2009, $15)$.

Tekanan darah pada lansia yang mengalami hipertensi sesudah senam yoga

Tabel 5.7 menunjukkan bahwa dari 20 responden sebagian besar tekanan darah pada lansia yang mengalami hipetensi sesudah senam yoga termasuk dalam kategori normal tinggi yaitu sejumlah 11 responden $(55 \%)$.

Menurut peneliti terjadinya penurunan tekanan darah pada lansia dikarenakan lansia sudah melakukan senam yoga. Dengan melakukan Latihan yoga menstimulasi pengeluaran hormon endorphin. Endorphin adalah neuropeptide yang dihasilkan tubuh pada saat relaks/tenang. Endorphin dihasilkan di otak dan susunan syaraf tulang belakang. Hormon ini dapat berfungsi sebagai obat penenang alami yang diproduksi otak yang menyalurkan rasa nyaman dan meningkatkan kadar endorphin dalam tubuh untuk mengurangi tekanan darah tinggi.

Menurut Jain (2011, 3), yoga merupakan suatu mekanisme penyatuan dari tubuh, pikiran dan jiwa. Yoga mengkombinasikan teknik respirasi, relaksasi dan meditasi serta peregangan. Yoga dapat disarankan menjadi terapi pada penderita hipertensi, hal ini dikarenakan efek menenangkan yang dihasilkan dapat memperlancar sirkulasi darah yang mengindikasikan kerja sistem kardiovaskuler berjalan dengan baik (Ridwan, 2009, 3). Perpaduan antara meditasi dan yoga pada penderita hipertensi, dengan mengobservasi tekanan darah tinggi menggunakan alat elektronik didapatkan hasil sebagian sudah berhenti mengkonsumsi obat dan sebagian besar sudah mulai mengurangi konsumsi obat (Jain, 2011, 3).

\section{Pengaruh senam yoga terhadap penurunan tekanan darah pada lansia yang mengalami hipertensi}

Tabel 5.8 menunjukkan bahwa dari 20 responden tekanan darah pada lansia yang mengalami hipertensi sebelum senam yoga termasuk dalam kategori sedang akan meningkatkan penurunan tekanan darah pada lansia yang mengalami hipertensi 
sesudah senam yoga menjadi kategori ringan sejumlah 8 responden (40\%). Hasil uji statistik Wilcoxon diperoleh angka signifikan atau nilai probabilitas $(0,000)$ jauh lebih rendah standart signifikan 0,05 atau $(\mathrm{p}<\alpha)$, dikarenakan $\mathrm{p}<\alpha$, yang berarti ada pengaruh senam yoga terhadap penurunan tekanan darah pada lansia yang mengalami hipertensi di Desa Plandi Kecamatan Jombang Kabupaten Jombang.

Menurut peniliti, menurunnya tekanan darah pada responden dikarenakan responden bersungguh-sungguh dan percaya jika terapi senam yoga dapat menurunkan tekanan darahnya. Sehingga, latihan yoga selama tiga kali dalam satu minggu dapat menunjukkan hasil yang maksimal.

Menurut Jain, (2011, 3) terdapat beberapa jenis senam yoga yang memiliki banyak manfaat, salah satunya jenis senam yoga yang khusus untuk menangani hipertensi pada lansia. Bernapas adalah suatu tindakan yang otomatis tanpa harus diperintah untuk melakukannya. Tetapi, jika kita bernapas dengan cepat dan dangkal akan mengurangi jumlah oksigen yang tersedia dan otak akan bereaksi terhadap hal ini dengan panik, sehingga terjadilah peningkatan denyut jantung dan peningkatan tekanan darah. Dengan mengatur napas menjadi lebih pelan dan dalam akan membuat peregangan pada otot-otot tubuh. Hal ini menyebabkan tubuh dan pikiran menjadi lebih relaks, nyaman dan tenang yang membuat penurunan pada tekanan darah. Pranayama (teknik bernapas) pada yoga berfungsi untuk menenangkan pikiran dan tubuh yang membuat detak jantung lebih tenang sehingga tekanan darah dan produksi hormon adrenalin menurun.

\section{KESIMPULAN DAN SARAN}

\section{Kesimpulan}

1. Tekanan darah pada lansia yang mengalami hipertensi sebelum senam yoga di Desa Plandi Kecamatan Jombang Kabupaten Jombang sebagian besar termasuk dalam kategori sedang.

2. Tekanan darah pada lansia yang mengalami hipertensi sesudah senam yoga di Desa Plandi Kecamatan Jombang Kabupaten Jombang sebagian besar termasuk dalam kategori normal tinggi.

3. Ada pengaruh senam yoga terhadap penurunan tekanan darah pada lansia yang mengalami hipetensi di Desa Plandi Kecamatan Jombang Kabupaten Jombang.

\section{Saran}

1. Bagi perawat ponkesdes

Bagi perawat pondok kesehatan desa hendaknya memberikan intervensi untuk melakukan senam yoga secara rutin agar bisa menurunkan tekanan darah pada lansia yang mengalami hipertensi.

2. Bagi dosen

Bagi dosen diharapkan bisa menjadi bahan referensi bagi mahasiswa tentang senam yoga terhadap penurunan tekanan darah pada lansia yang mengalami hipertensi. 
3. Bagi responden

Diharapkan responden mengerti manfaat serta melaksanakan senam yoga untuk penurunan tekanan darah.

4. Bagi peneliti selanjutnya Peneliti selanjutnya diharapkan dapat mengembangkan bahasan tentang senam yoga untuk penurunan tekanan darah pada lansia yang mengalami hipertensi.

\section{DAFTAR PUSTAKA}

Depkes, 2016. Prevelensi hipertensi. http://www.pps.unud.ac.id/thesis.p df. Diakses 10/03/2017.

Dinas Komunikasi dan Informatika Prov.Jatim, 2015. Jumlah lansia. Dinas komunikasi Provinsi Jatim.

Jain, 2011. Senam yoga. http://download.portalgaruda.org/a rticle.php. Diakses 11/03/2017.

Profil Kesehatan Jombang. 2015. Data Hipertensi di Jombang. Dinkes Jombang.

Ridwan, 2009. Hipertensi. http://download.portalgaruda.org/a rticle.php. Diakses 11/03/2017.

Santoso. 2010. Membonsai Hipertensi. Surabaya. Temprina Media Grafika.

Sheps, 2009. Aktifitas fisik pada lansia. http://download.portalgaruda.org.p hp. Diakses 11/03/2017.
Sindhu, 2011. Latihan Yoga. http://download.portalgaruda.org/a rticle.php. Diakses 11/03/2017.

Sugiyono. 2010. Metode Penelitian Bisnis. Bandung: $\mathrm{Cv}$ Alfa Beta

Yusuf,2011. Penyebab hipertensi. http://download.portalgaruda.org/a rticle.php. Diakses 11/03/2017 
